\title{
Factors regulating the growth of the preovulatory follicle in the sheep and human
}

\author{
D. T. Baird \\ Department of Obstetrics and Gynaecology, University of Edinburgh, Centre for Reproductive \\ Biology, 37 Chalmers Street, Edinburgh EH3 9EW, U.K.
}

\begin{abstract}
Summary. Around the time of luteal regression in monovular species a single dominant follicle, which will eventually ovulate, is selected from the population of antral follicles. The dominant follicle is characterized by its progressive increase in diameter due to increase in antral fluid volume as well as an increased number of granulosa cells. The crucial factor in the continued development of the dominant follicle is its ability to synthesize oestradiol under the influence of LH and FSH. In the sheep FSH secretion continues throughout the luteal phase while LH is suppressed. Thus development of large antral follicles continues so that when luteal regression occurs and LH secretion increases the final stages of development of the pre-antral follicle occur within 3 days. In the human, however, both FSH and LH are suppressed during the luteal phase and only rise when the levels of progesterone and oestradiol fall a few days before menstruation. This rise in FSH and LH which occurs at this time stimulates the further development of a small antral follicle (1-2 mm diameter). Within 7 days the favoured follicle establishes dominance over the other asynchronously developing follicles probably by inhibiting the secretion of FSH. As in the sheep, once aromatase enzyme(s) has been fully activated the dominant follicle is able to utilize the increased androgen precursor produced by the theca under LH stimulation.
\end{abstract}

\section{Introduction}

In most mammals the final stage of folliculogenesis is characterized by the emergence of a minority of large antral follicles which will eventually ovulate (Mauléon \& Marianna, 1977). The mechanism by which individual follicles are selected for ovulation is unknown although it is now clear that once established these follicles suppress further development of other large antral follicles. Even in those species that usually only have a single ovulation the total number of antral follicles $>1 \mathrm{~mm}$ diameter present in the ovary during the cycle greatly exceeds the number which ovulate, e.g. women: 6-46 per ovary; sheep: 5-24 (McNatty, 1982). This paper will consider how the preovulatory follicle is selected and the way in which it establishes dominance over the other antral follicles in the human and sheep.

\section{The preovulatory dominant follicle}

Immediately before ovulation the preovulatory follicle in ewes and women is easily recognized macroscopically by its size and vascular appearance. The vascularity is due to a large capillary network supplying the theca interna and is presumably induced by some product of the growing 
antral follicle, e.g. oestrogen. In both species there is usually only one large follicle in the late follicular phase of the cycle which contains a full complement of healthy granulosa cells (McNatty, 1982). The dominant follicle secretes large amounts of oestradiol into the ovarian vein. In the human by Day 7 (mid-follicular phase) the largest healthy antral follicle has already established dominance, as indicated by the asymmetry in the concentration of oestradiol in blood draining the two ovaries (Baird \& Fraser, 1975) and by the marked fall in oestradiol concentration in peripheral blood following its surgical removal (Nilsson, Wikland \& Hamberger, 1982). Similar evidence in the sheep indicates that over $95 \%$ of the oestradiol entering the ovarian vein originates from the largest non-atretic antral follicle in both the luteal and follicular phase of the cycle (Moor, Hay \& Seamark, 1975; Baird \& Scaramuzzi, 1976a).

The cellular origin of follicular oestradiol has been the source of some controversy (Armstrong, Weiss, Selstam \& Seamark, 1981; McNatty, 1982). In women and ewes androgens are the main steroids synthesized by the theca cells while the aromatase activity of the granulosa cells is much higher than that of the theca cells (Hillier, Reichert \& van Hall, 1981). It is generally assumed, therefore, that some form of interaction occurs between the two cell types in the ovarian follicle with LH stimulating the theca cells to synthesize androgens which are then converted to oestrogens by the granulosa cells. Although there is strong evidence that oestrogen synthesis is enhanced when the two cell types are mixed in vitro (e.g. Ryan, Petro \& Kaiser, 1968), convincing evidence that this accurs in vivo is provided by experiments in which antiserum to testosterone was infused into the ovarian artery of sheep ovaries bearing the preovulatory follicle (Baird, 1977) (Text-fig. 1). Oestradiol secretion was inhibited by over $50 \%$ during and immediately after the infusion of antiserum to testosterone (but not during infusion of antiserum to BSA or oestrone). As it seems unlikely that the antibodies could enter the theca cells, these experiments support the hypothesis that androgen precursors leave the theca cells before being aromatized to oestrogens.

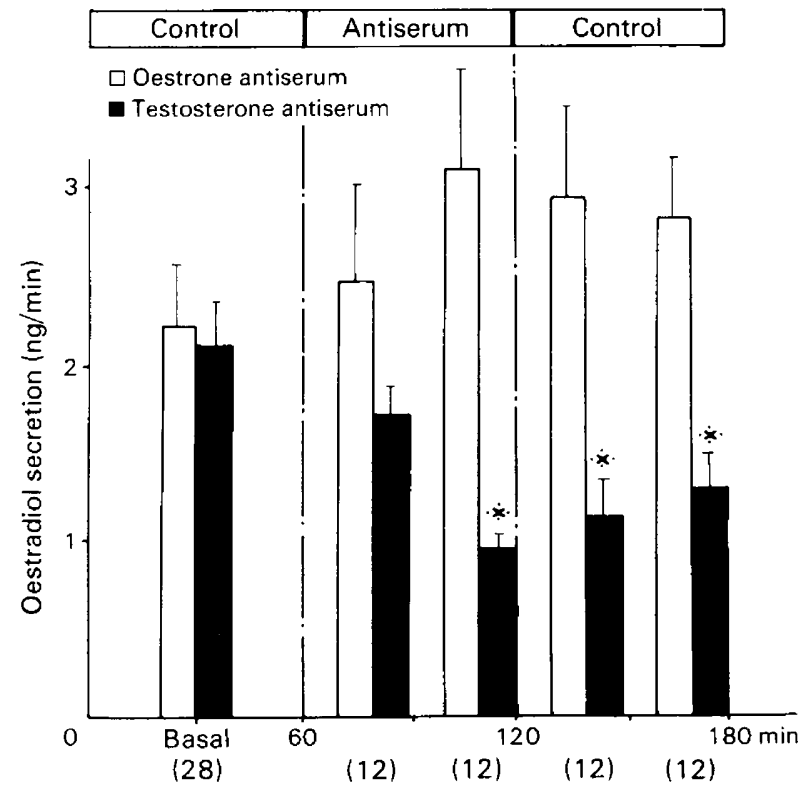

Text-fig. 1. The effect of antiserum to testosterone on the secretion of oestradiol from the sheep ovary during the follicular phase of the cycle. Control antiserum to BSA was infused via the ovarian artery during $0-60$ and $120-180 \mathrm{~min}$ in 8 sheep with ovaries autotransplanted to the neck. From 60 to $120 \mathrm{~min}$ antiserum to testosterone (4 ewes) or oestrone (4 ewes) was infused. Each bar represents the mean \pm s.e.m. of 28 or 12 observations in 4 sheep. (Data from Baird, 1977). * Significantly different from basal value and that for animals treated with antiserum to oestrone $(P<0.05)$. 
In addition to being 'oestrogenic', the preovulatory follicle has other characteristics. The most 'oestrogenic follicle' has more granulosa cells and is more likely to contain measurable amounts of FSH than is the 'non'-oestrogenic' follicle (Text-fig. 2) (McNatty \& Baird, 1978; McNatty, 1982). FSH stimulates the aromatase activity of cultured granulosa cells from sheep and human antral follicles. In the few days before ovulation the concentration of androgens (androstenedione and testosterone) falls significantly in the follicular fluid of the dominant follicle in contrast to that of other antral follicles (McNatty et al., 1976). It seems likely, therefore, that the dominant follicle manages to maintain a very high secretion of oestradiol because of the large number of granulosa cells with a maximally activated aromatase system.

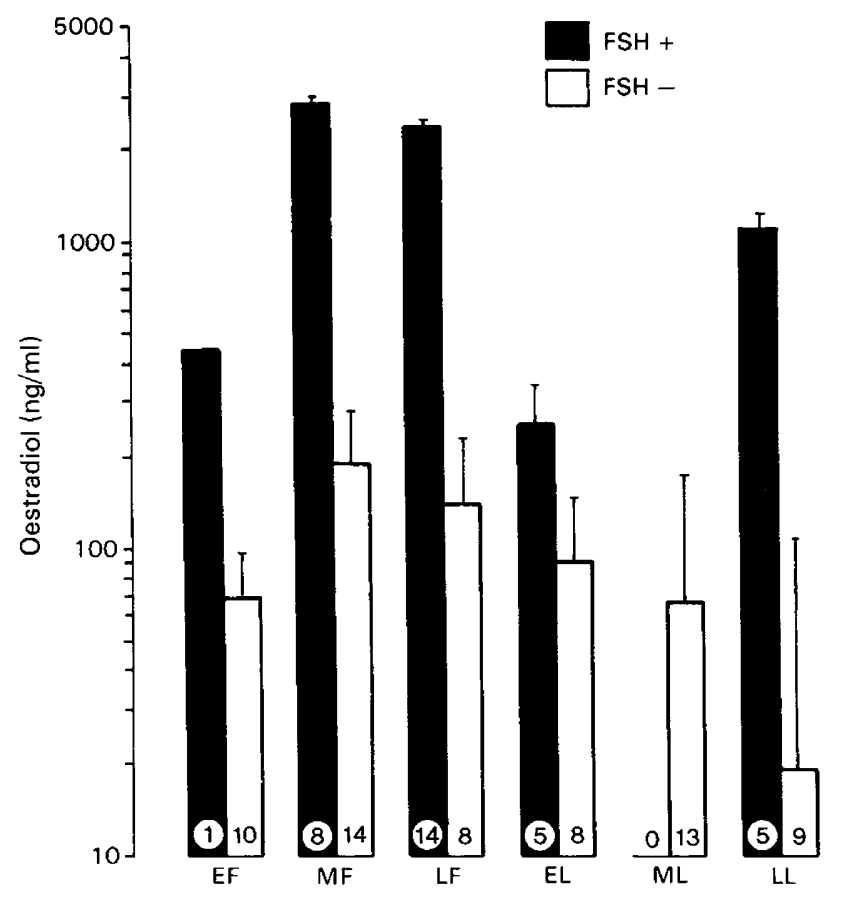

Text-fig. 2. Mean \pm s.e.m. concentration of oestradiol in follicular fluid throughout the menstrual cycle. The follicles were divided into those with detectable amounts of FSH $(>1.3$ $\mathrm{mU} / \mathrm{ml}: \mathrm{FSH}+$ ) and those with undetectable levels (FSH -). The numbers indicate the number of fluid samples in each group. EF, MF and LF, early, mid- and late follicular phases respectively. EL, ML and LL, early, mid- and late luteal phases respectively. (Data from McNatty \& Baird, 1978.)

In the sheep, receptors for $\mathrm{LH}$ are present on thecal cells of healthy and atretic follicles although they are confined to the granulosa cells of large healthy antral follicles (Carson, Findlay, Burger \& Trounson, 1979). Evidence from the rat suggests that both oestradiol and FSH play an important role in the acquisition of LH receptors by the granulosa cells (Richards \& Midgley, 1976). It seems likely that only those follicles in which the granulosa cells contain LH receptors can ovulate in response to the mid-cycle LH surge.

In summary, the dominant preovulatory follicle in both species is characterized by the synthesis of large amounts of oestradiol due to the ability of its granulosa cells to aromatise androgen precursors synthesized by the theca interna. 

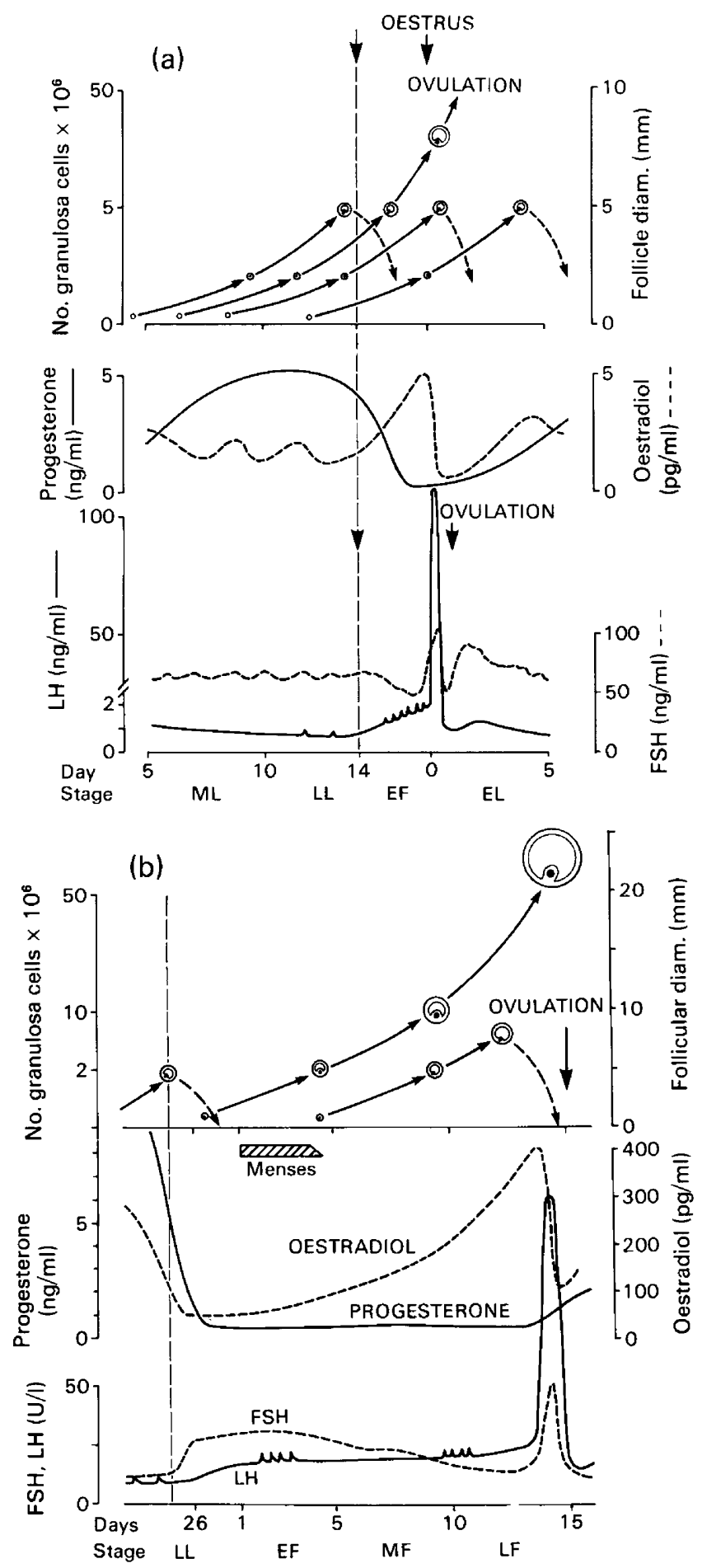

Text-fig. 3. Development of the preovulatory follicle in (a) the sheep and (b) the human. In the sheep, follicular development continues throughout the luteal phase because of the relatively high levels of FSH. In the human, development of large antral follicles is suppressed during the luteal phase and only recommences when the levels of FSH and LH rise at luteal regression. EF $=$ early follicular; $\mathrm{MF}=$ mid-follicular $; \mathrm{LF}=$ late follicular $; \mathrm{EL}=$ early luteal $; \mathrm{ML}=$ midluteal; $\mathbf{L L}=$ late luteal. The broken vertical line indicates the onset of luteal regression. 


\section{When is the dominant follicle selected?}

In both the sheep and the human the preovulatory follicle becomes dominant in the few days following regression of the corpus luteum. In the sheep, ovulation occurs within 3 days of natural or induced luteal regression while the equivalent period in the human is 17 days (Baird \& McNeilly, 1981; Nilsson et al., 1982). This difference cannot be explained by differences in the rate of follicular development (Text-fig. 3) but is due to the fact that, in the sheep, in contrast to the human, development of large antral follicles (4-6 mm diameter) continues throughout the luteal phase (Turnbull, Braden \& Mattner, 1977; Cahill, Marianna \& Mauléon, 1979; Gougeon, 1982). We have previously suggested that this difference in follicular development is related to the different pattern of steroid hormones secreted by the corpora lutea of the two species-with consequent differences in secretion of gonadotrophins (Baird, Baker, McNatty \& Neal, 1975).

The changes in the concentration of pituitary gonadotrophins and ovarian steroids at luteal regression and the periovulatory period in the sheep are illustrated in Text-fig. 3. The decline in progesterone secretion at luteal regression is followed by a rise in the concentration of $\mathrm{LH}$ and oestradiol but no change in the secretion of FSH (Baird, Swanston \& McNeilly, 1981). Following prostaglandin-induced luteal regression there is a 3-fold rise in the secretion of $\mathrm{LH}$ which is accompanied by a rise in the secretion of oestradiol (Text-fig. 4). If the levels of progesterone are restored by the subcutaneous insertion of a progesterone-impregnated implant, the concentration of $\mathrm{LH}$ and the secretion of oestradiol are suppressed to the levels found during the luteal phase. These observations suggest that progesterone plays an important role in regulating the secretion of LH during the luteal phase (Hauger, Karsch \& Foster, 1977) and that the preovulatory rise in the secretion of oestradiol is dependent on the increased secretion of LH which occurs after luteal

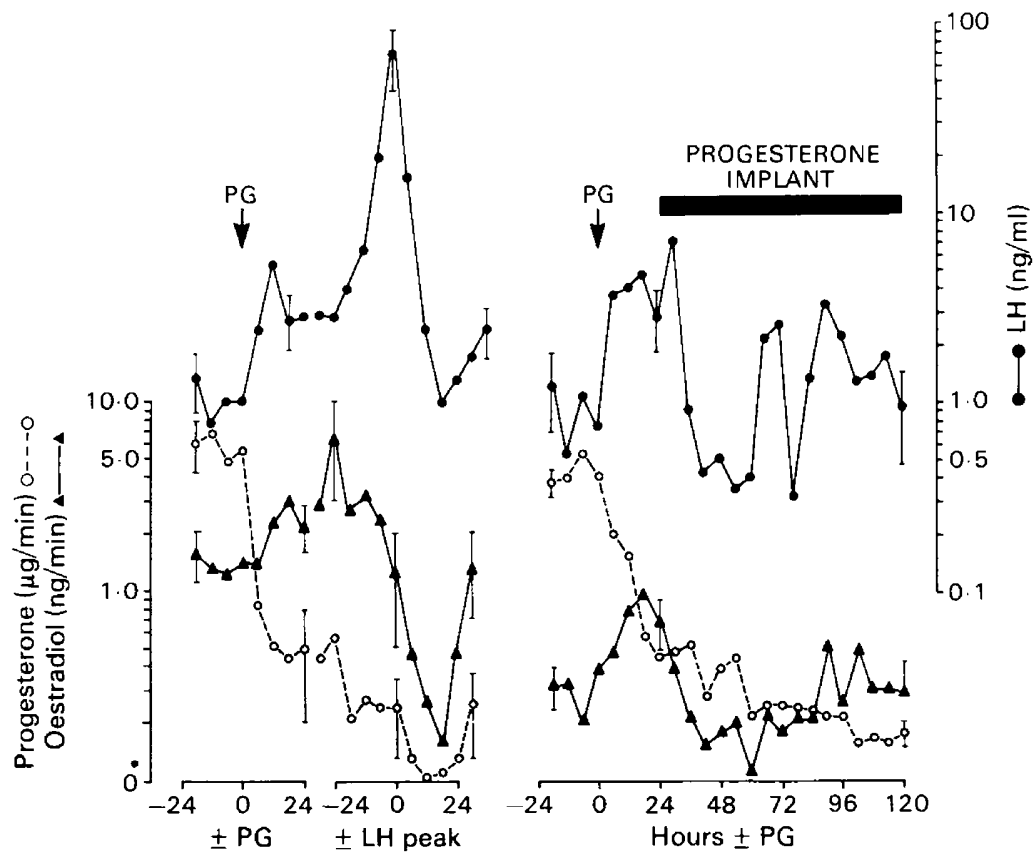

Text-fig. 4. Concentration of LH and ovarian secretion of oestradiol and progesterone in the sheep following luteal regression induced by injection of $50 \mu \mathrm{g}$ cloprostenol (PG). Each point represents the mean values of 6 ewes with ovarian autotransplants. A progesteroneimpregnated silicone-rubber implant was inserted $24 \mathrm{~h}$ after $P G$ injection in some of the sheep (right). The s.e. have been omitted from most of the points for the sake of clarity. (Data from Baird \& Scaramuzzi, 1976b). 
regression (Baird, 1978). In contrast, the concentration of FSH remains relatively unchanged throughout the luteal phase and the initial stages of luteal regression and is suppressed by about $30 \%$ only immediately before the preovulatory surge of FSH and LH (Text-fig. 5). This decline in FSH also occurs when ovulation is induced in anoestrus by PMSG (D.T. Baird \& A. S. McNeilly, unpublished observations) or by pulsatile administration of LH (McNeilly, O'Connell \& Baird, 1982) and is coincidental to maximum secretion of oestradiol. As oestradiol is known to inhibit FSH, it seems likely that these two events are causally related, i.e. secretion of oestradiol from the preovulatory follicle is responsible for the suppression of FSH at this time, although the simultaneous secretion of other factors, e.g. inhibin, cannot be excluded.

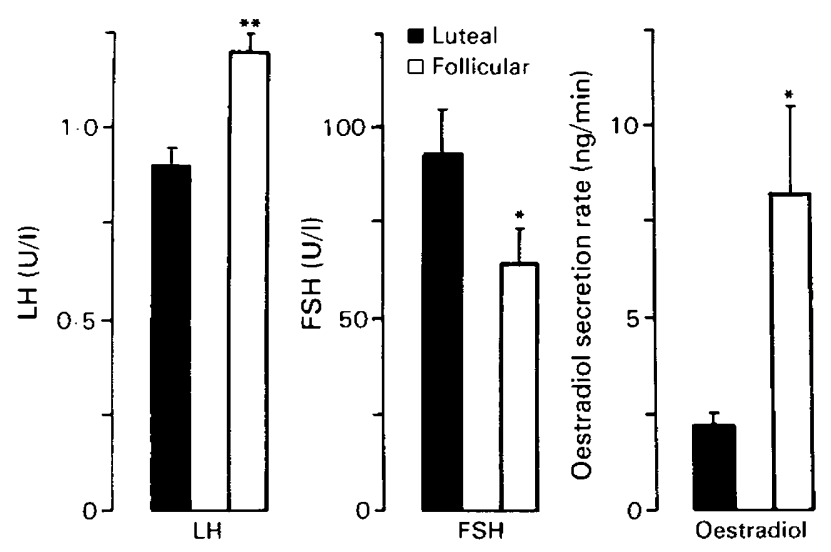

Text-fig. 5. Change in concentration of $\mathrm{LH}$ and FSH and ovarian secretion of oestradiol in the sheep oestrous cycle. Each bar is the mean \pm s.e.m. of the values in 5 sheep on Day 10 (luteal) and $24 \mathrm{~h}$ after prostaglandin-induced luteal regression (follicular). (Data from Baird et al., 1981.) ${ }^{*} P<0.05 ;{ }^{* *} P<0.01$.

When then is the dominant follicle selected in the sheep? It seems unlikely that it occurs before luteal regression because surgical enucleation of the corpus luteum at any stage is followed by ovulation about $72 \mathrm{~h}$ later. The fact that a compensatory increase in ovulation rate can occur if unilateral oophorectomy is performed as late as Day 14 again supports the fact that follicle selection occurs after luteal regression (Land, 1973). Following regression of the corpus luteum there is a marked decline in the percentage of healthy antral follicles and by $36 \mathrm{~h}$ after luteolysis all but the preovulatory follicle(s) are atretic (McNatty et al., 1982). In the sheep, therefore, the final selection of the preovulatory follicle occurs early in the follicular phase.

In the human, in contrast to the sheep, development of antral follicles is suppressed during the luteal phase as indicated by the fact that all follicles $>4 \mathrm{~mm}$ diameter are atretic (McNatty, 1982). That suppression of antral development during the luteal phase of the primate cycle is due to the low levels of FSH and LH is supported by the fact that follicular development can be induced during the luteal phase of the rhesus monkey by injection of exogenous gonadotrophin (hMG) (di Zerega \& Hodgen, 1980). However, because this preparation contains both FSH and LH in equivalent amounts, it is not possible to say whether FSH or LH or both is the critical stimulatory agent.

It seems likely that the low levels of FSH and LH during the luteal phase of the cycle are due to the negative feedback effect of oestradiol and progesterone secreted by the corpus luteum. As the concentration of these steroids declines at the end of the luteal phase the concentration of FSH and LH rises (Text-fig. 3). If the corpus luteum is enucleated surgically at any stage of the luteal phase follicular growth recommences and ovulation occurs about 18 days later (D. T. Baird, C. T. Bäckström, A. S. McNeilly, S. Smith \& C. Wathen, unpublished observations). The fact that the emergence of the dominant follicle as indicated by a rise in oestradiol concentration is preceded in 
the human by a rise in FSH and LH concentration supports the view that suppression of gonadotrophins by ovarian steroids is responsible for the inhibition of follicular development during the luteal phase of the primate cycle.

In similar experiments in the rhesus monkey, Goodman \& Hodgen (1977) were unable to demonstrate any rise in gonadotrophins after enucleation of the corpus luteum and therefore concluded that the suppressive effect of the corpus luteum was due to a local inhibitory effect of progesterone on follicular development. However, the increment in FSH which is necessary to induce development of the preovulatory follicle is probably small (see below) and may not have been detected because of the infrequent sampling regimen or the relatively insensitive, non-specific assays. The modest $30 \%$ rise in the concentration of FSH which occurs $5-12 \mathrm{~h}$ after unilateral ovariectomy in the ewe is transient, with levels returning to basal values within $12 \mathrm{~h}$ (Cumming \& Findlay, 1976).

By comparing these two species we can conclude that it seems likely that a minimum concentration of FSH as well as LH is required for development of large antral follicles. In the sheep this concentration is always present during the luteal phase and hence FSH can be considered to be permissive; in the human, reactivation of antral follicles will only occur when the secretion of FSH rises after luteal regression. If this rise in FSH is suppressed by porcine follicular fluid or oestradiol in monkeys (di Zerega \& Hodgen, 1981 ; Zeleznik, 1981) or ethinyl oestradiol in women (Van Look, Hunter, Fraser \& Baird, 1978), emergence of the dominant follicle is delayed. The exact way in which FSH activates follicular development is unknown, although it seems likely that it is necessary to convert the small healthy antral follicle $(1-2 \mathrm{~mm})$ into a structure which is capable of generating large amounts of oestrogen. In this way the 'chosen' follicle is able to benefit from the increased amount of androgen precursor produced by the theca cells in response to the increased secretion of LH which also occurs at this time.

The importance of the appropriate ratio of FSH and LH in ensuring normal development of the antral follicle is demonstrated in polycystic ovarian disease. This condition is characterized by chronic anovulation associated with the presence of numerous antral follicles about 5-10 mm diameter which secrete very little oestradiol and large quantities of androstenedione and testosterone (Yen, 1980). The pattern of gonadotrophin secretion is abnormal with chronically raised levels of LH and suppressed levels of FSH. Thus the theca cells of the follicles are stimulated to secrete large quantities of androgens which cannot be converted to oestrogens because the granulosa cells are deficient in aromatase. Addition of FSH, in vivo or in vitro, causes a rapid increase in oestradiol secretion and normal follicular development (Erickson, Hsueh, Quigley, Rebar \& Yen, 1979).

\section{How is the dominant follicle selected?}

What causes selection of the dominant follicle in monovular species? If we accept that folliculogenesis is a continuous process then the most likely explanation of follicle selection is based on chance. We have seen that in both the sheep and human the dominant follicle acquires an increased capacity to synthesize oestradiol and that an oestrogenic environment appears to be essential for further development. At the time of luteal regression in the sheep there is an increase in the frequency of LH pulses which stimulates increased androgen synthesis by the theca (Baird, 1978). Only those antral follicles of $2-4 \mathrm{~mm}$ diameter, the granulosa cells of which have a very high aromatase activity, can maintain a highly oestrogenic environment by converting the androgens to oestradiol. The rising level of oestradiol secreted by the dominant follicle into the ovarian vein suppresses the secretion of FSH, ensuring that those follicles which are at a slightly less advanced stage of development are deprived of FSH (Text-fig. 5). The fall in the concentration of FSH which is detrimental to all but the dominant follicle may be quite modest. The decline in the proportion of healthy antral follicles $>1 \mathrm{~mm}$ diameter from about $50 \%$ on Day 12 to less than $20 \% 24 \mathrm{~h}$ after luteal regression is induced with cloprostenol is accompanied by only a $30 \%$ fall in the concentra- 
tion of FSH. The fact that this decline in incidence of healthy follicles can be prevented by simultaneous injection of PMSG supports the suggestion that lack of FSH is responsible for the increased incidence of atresia (McNatty et al., 1982).

In women the time taken for the emergence of the dominant follicle during the follicular phase is prolonged to 17 days due in part to the low levels of FSH during the luteal phase. The fall in progesterone and oestradiol concentration which occurs during luteal regression is followed by a rise in the concentration of both FSH and LH. The LH pulse frequency increases from $<1$ per $6 \mathrm{~h}$ during the mid-luteal phase to nearly 4 per $6 \mathrm{~h}$ in the early follicular phase (Bäckström, McNeilly, Leask \& Baird, 1982). This presumably reflects a gradual increase in the frequency of pulsatile release of Gn-RH and is probably responsible for the relatively greater increase in the concentration of FSH than LH. Based on doubling times and mitotic index, it has been calculated that the dominant follicle is about $1 \mathrm{~mm}$ diameter at the end of the luteal phase (Gougeon, 1982). Thus we could postulate that only the single antral follicle which is at this crucial stage of development can benefit from the rise of FSH and equip its granulosa cells with sufficient aromatase activity to maintain an oestrogenic environment in the face of increased thecal androgen synthesis stimulated by rising levels of LH. Direct evidence concerning the exact size of antral follicles at which this crucial switch, from an androgenic to an increasingly oestrogenic environment, occurs is lacking due to inability to isolate the population of small antral follicles at the appropriate stage of the cycle. However cross-sectional studies indicate that only a minority of small antral follicles (about $4 \mathrm{~mm}$ ) in the early follicular phase of the cycle contain high concentrations of oestrogen and detectable FSH (McNatty, Hunter, McNeilly \& Sawers, 1975). By Day 7 the dominant follicle has emerged and there is only a single follicle $>8 \mathrm{~mm}$ diameter which contains a full complement of granulosa cells and which maintains a highly oestrogenic follicular fluid (McNatty \& Baird, 1978). As the oestrogen secretion from this dominant follicle increases, the concentration of FSH falls. That this fall in FSH is probably responsible for inhibiting the further development of other antral follicles is supported by the fact that administration of exogenous FSH in the form of hMG during the follicular phase stimulates the development of more than one preovulatory follicle (Edwards et al., 1972). The difficulty in preventing multiple ovulation when using exogenous gonadotrophin reflects the very subtle regulation in the secretion of endogenous gonadotrophin by the hypothalamus and pituitary in the spontaneous cycle. Brown (1978) has argued that within the same individual the difference in dose of gonadotrophin between no effect and stimulation of follicular development may be as little as $20 \%$ and that the 'threshold' dose necessary to maintain follicular development changes with the size of the follicle. Thus, minor changes in the concentration of FSH in the spontaneous cycle probably have important biological effects on the ovary.

\section{What determines ovulation rate?}

Although most women and ewes of many breeds of sheep usually have single ovulations, multiple ovulations do occur. Dizygotic twinning is more common in older women and in certain ethnic groups, e.g. the Igbo-Ora tribe in Nigeria have a rate of dizygotic twins four times that of most European countries (Nylander, 1975). Although it is possible that differences in twinning rate reflect differential embryonic mortality, studies in sheep have demonstrated well marked genetic differences in ovulation rate.

If we accept the model for selection of the dominant follicle outlined above, development of more than one dominant follicle could be achieved by two main mechanisms. (1) The number of antral follicles reaching the crucial stage of development could be increased so that the chance of more than one follicle being ready to benefit from the rise in the concentration of LH (and FSH in the human) at the time of luteal regression is increased. (2) The hypothalamic-pituitary system could be less sensitive to the negative feedback effects of oestrogen so that higher levels of oestradiol were 'tolerated' before the secretion of FSH was suppressed. In this way the chance of recruiting more than one healthy follicle for development to ovulation would be increased. 
The available evidence suggests that both mechanisms operate. In high fertility breeds of sheep (Romanov and Finnish Landrace) the number of antral follicles of all sizes is increased although the total population of follicles, including preantral follicles, is reduced compared to that in low fertility breeds (Cahill et al., 1979). It therefore seems likely that on any day a greater number of antral follicles are proceeding through the terminal growth phase. In addition some high fertility breeds (Finn and Romanov) are more resistant to the feedback effects of oestrogen (Land, 1976). Thus during the follicular phase, although the levels of oestradiol are higher in the high fertility breeds, the levels of FSH are similar or even slightly higher than in the low fertility breeds (Cahill, 1981). In spite of the higher secretion of oestrogen, the LH surge occurs slightly later in oestrus in the Romanov (Land, Pelletier, Thimonier \& Mauléon, 1973). If there were no difference in the sensitivity to positive feedback the LH surge would occur at an earlier stage in maturation of the preovulatory follicle, as appears to occur in the Booroola strain of Merino. In the follicular phase this high fertility ewe has more than double the number of high-oestrogenic preovulatory follicles, the diameter of which is lower than that in the low fertility control $(4.5 \pm 0.16$ compared with $6.0 \pm$ $0.35 \mathrm{~mm}$ respectively) (D. T. Baird, M. M. Ralph, B. M. Bindon, F. Amato \& R. F. Seamark, unpublished results). Thus the follicles of this ewe appear to ovulate at an earlier stage of follicular development and the subsequent corpora lutea are correspondingly smaller.

As gonadotrophins are essential for normal follicular development and injection of exogenous gonadotrophins containing FSH activity increases the number of preovulatory follicles, it seems reasonable to assume that an increased secretion of FSH may be important in maintaining the ovulation rate in high fertility breeds of sheep. Numerous studies have failed to reveal major differences in the levels of FSH in breeds of widely differing ovulation rates (Cahill, 1981). However, before concluding that differences in the secretion of gonadotrophins are unimportant in determining ovulation rate, it should be remembered that in the individual animal the differences in the concentration of FSH which may be biologically significant may be much smaller than differences between individuals (Brown, 1978). Moreover, because of the feedback mechanisms operating in the intact animal a difference in GTH values may occur for a short period only when the system is perturbed and may be difficult to detect by existing methods. Studies comparing the gonadotrophin levels in sheep of low and high fecundity which are implanted with steroids after ovariectomy would help to elucidate whether there are major differences in sensitivity to steroid feedback.

\section{References}

Armstrong, D.T., Weiss, T.J., Selstam, G. \& Seamark, R.F. (1981) Hormonal and cellular interactions in follicular steroid biosynthesis by the sheep ovary. $J$. Reprod. Fert., Suppl. 30, 143-154.

Bäckström, C.T., McNeilly, A.S., Leask, R.M. \& Bairrd, D.T. (1982) Pulsatile secretion of LH, FSH, prolactin, oestradiol and progesterone during the human menstrual cycle. Clin. Endocr. 17, 29-42.

Baird, D.T. (1977) Evidence in vivo for the two-cell hypothesis of oestrogen synthesis by the sheep Graafian follicle. J. Reprod. Fert. 50, 183-185.

Baird, D.T. (1978) Pulsatile secretion of LH and ovarian estradiol in the follicular phase of the sheep estrous cycle. Biol. Reprod. 18, 359-364.

Baird, D.T. \& Fraser, I.S. (1975) Concentration of oestrone and oestradiol-17 $\beta$ in follicular fluid and ovarian venous blood of women. Clin. Endocr. 4, 259266.

Baird, D.T. \& McNeilly, A.S. (1981) Gonadotrophic control of follicular development and function during the oestrous cycle of the ewe. J. Reprod. Fert., Suppl. 30, 119-133.
Baird, D.T. \& Scaramuzzi, R.J. (1976a) The source of ovarian oestradiol and androstenedione in the sheep during the luteal phase. Acta endocr., Copenh. 83, $402-409$.

Baird, D.T. \& Scaramuzzi, R.J. (1976b) Changes in the secretion of ovarian steroids and pituitary luteinizing hormone in the peri-ovulatory period in the ewe: the effect of progesterone. J. Endocr. 70, 237245.

Baird, D.T., Baker, T.G., McNatty, K.P. \& Neal, P. (1975) Relationship between the secretion of the corpus luteum and the length of the follicular phase of the ovarian cycle. J. Reprod. Fert. 45, 611619.

Baird, D.T., Swanston, I.A. \& MeNeilly, A.S. (1981) Relationship between LH, FSH and prolactin concentration and the secretion of androgens and estrogens by the preovulatory follicle in the ewe. Biol. Reprod. 24, 1013-1025.

Brown, J.B. (1978) Pituitary control of ovarian function-concepts derived from gonadotrophin therapy. Aust. N.Z. J. Obstet. Gynaec. 18, 47-54.

Downloaded from Bioscientifica.com at 04/26/2023 09:14:45AM 
Cahill, L.P. (1981) Folliculogenesis in the sheep as influenced by breed, season and oestrous cycle. $J$. Reprod. Fert., Suppl. 30, 135-142.

Cahill, L., Marianna, J.C. \& Mauléon, P. (1979) Total follicular populations in ewes of high and low ovulations rates. J. Reprod. Fert. 55, 27-36.

Carson, R.S., Findlay, J.K., Burger, H.G. \& Trounson, A.O. (1979) Gonadotropin receptors of the ovine ovarian follicle during follicular growth and atresia. Biol. Reprod. 21, 75-87.

Cumming, I.A. \& Findlay, J.K. (1976) FSH levels and unilateral ovariectomy in the ewe. J. Reprod. Fert. 46, 516-517.

di Zerega, G.S. \& Hodgen, G.D. (1980) Cessation of folliculogenesis during the primate luteal phase. $J$. clin. Endocr. Metab. 51, 158-160.

di Zerega, G.S. \& Hodgen, G.D. (1981) Folliculogenesis in the primate ovarian cycle. Endocr. Rev. 2, 27-49.

Edwards, R.G., Steptoe, P.C., Abraham, G.E., Walters, D.E., Purdy, J.M. \& Fotherby, K. (1972) Steroid assays and pre-ovulatory follicular development in human ovaries primed with gonadotrophins. Lancet i, $611-615$.

Erickson, G.F., Hsueh, A.J.W., Quigley, M.E., Rebar, R.W. \& Yen, S.S.C. (1979) Functional studies of aromatase activity in human granulosa cells from normal and polycystic ovaries. J. clin. Endocr. Metab. 49, 514-519.

Goodman, A.L. \& Hodgen, G.D. (1977) Systemic versus intra-ovarian progesterone replacement after luteectomy in rhesus monkeys: differential patterns of gonadotrophins and follicle growth. J. clin. Endocr. Metab. 45, 837-840.

Gougeon, A. (1982) Rate of follicular growth in the human ovary. In Follicular Maturation and Ovulation, pp. 155-163. Eds R. Rolland, E. V. van Hall, S. G. Hillier, K. P. McNatty \& J. Schoemaker. Excerpta Medica, Amsterdam.

Hauger, R.L., Karsch, F.J. \& Foster, D.L. (1977) A new concept for control of the estrous cycle of the ewe based on the temporal relationships between luteinizing hormone, estradiol and progesterone in peripheral serum and evidence that progesterone inhibits tonic LH secretion. Endocrinology 101, 807-817.

Hillier, S.G., Reichert, L.E., Jr \& van HaH, E.V. (1981) Control of pre-ovulatory follicular estrogen biosynthesis in the human ovary. J. clin. Endocr. Metab. 51, $847-856$.

Land, R.B. (1973) The ovulation rate of Finn-Dorset sheep following unilateral ovariectomy and chlorpromazine treatment at different stages of the oestrous cycle. J. Reprod. Fert. 33, 99-105.

Land, R.B. (1976) The sensitivity of the ovulation rate of Finnish Landrace and Blackface ewes to exogenous oestrogen. J. Reprod. Fert. 48, 217-218.

Land, R.B., Pelletier, J., Thimonier, J. \& Mauléon, P. (1973) A quantitative study of genetic differences in the incidence of oestrus, ovulation and plasma luteinizing hormone concentration in the sheep. $J$. Endocr. 58, 305-317.

Mauléon, P.\& Marianna, J.C. (1977) Oogenesis and folliculogenesis. In Reproduction in Domestic Animals, 2nd edn, pp. 175-198. Eds H. H. Cole \& P. R. Cupps. Academic Press, New York.
McNatty, K.P. (1982) Ovarian follicular development from the onset of luteal regression in human and sheep. In Follicular Maturation and Ovulation, pp. 118. Eds R. Rolland, E. V. van Hall, S. G. Hillier, K. P. McNatty \& J. Schoemaker. Excerpta Medica, Amsterdam.

McNatty, K.P. \& Baird, D.T. (1978) Relationship between follicle-stimulating hormone, androstenedione and oestradiol in human follicular fluid. $J$. Endocr. 76, 527-531.

McNatty, K.P., Hunter, W.M., McNeilly, A.S. \& Sawers, R.W. (1975) Changes in the concentration of pituitary and steroid hormones in the follicular fluid of human Graafian follicles throughout the menstrual cycle. $J$. Endocr. 64, 555-571.

McNatty, K.P., Baird, D.T., Bolton, A., Chambers, P.S., Corker, C.S. \& McLean, H. (1976) Concentration of oestrogens and androgens in human ovarian venous plasma and follicular fluid throughout the menstrual cycle. J. Endocr. 71, 77-85.

McNatty, K.P., Gibb, M., Dobson, C., Ball, K., Custer, J., Heath, D. \& Thurley, D.C. (1982) Preovulatory follicular development in sheep treated with PMSG and/or prostaglandin. J. Reprod. Fert. 65, 111-123.

McNeilly, A.S., O'Connell, M. \& Baird, D.T. (1982) Induction of ovulation and normal luteal function by pulsed injections of luteinizing hormone in anestrous ewes. Endocrinology 110, 1292-1299.

Moor, R.M., Hay, M.F. \& Seamark, R.F. (1975) The sheep ovary: regulation of steroidogenic, haemodynamic and structural changes in the largest follicle and adjacent tissue before ovulation. J. Reprod. Fert. 45, 595-604.

Nilsson, L., Wikland, M. \& Hamberger, L. (1982) Recruitment of an ovulatory follicle in the human following follicle-ectomy and luteectomy. Fert. Steril. 37, 30-34.

Nylander, P.P.S. (1975) Frequency of multiple births. In Human Multiple Reproduction, pp. 87-97. Eds 1 . McGillivray, P. P. Nylander \& G. Correy. Saunders, London.

Richards, J.S. \& Midgley, A.R., Jr (1976) Protein hormone action : a key to understanding ovarian follicular and luteal cell development. Biol. Reprod. 14, 89-94.

Ryan, K.J., Petro, Z. \& Kaiser, J. (1968) Steroid formation by isolated and recombined ovarian granulosa and theca cells. J. clin. Endocr. Metab. 28, 355-358.

Turnbull, K.E., Braden, A.W.H. \& Mattner, P.E. (1977) The pattern of follicular growth and atresia in the ovine ovary. Aust. J. biol. Sci. 30, 229-241.

Van Look, P.F.A., Hunter, W.M., Fraser, I.S. \& Baird, D.T. (1978) Impaired estrogen-induced luteinizing hormone release in young women with anovulatory dysfunctional uterine bleeding. J. clin. Endocr. $M e$ tab. 46, 816-823.

Yen, S.S.C. (1980) The polycystic ovary syndrome. Clin. Endocr. 12, 177-208.

Zeleznik, A.J. (1981) Premature elevation of systemic estradiol reduces serum levels of follicle stimulating hormone and lengthens the follicular phase of the menstrual cycle in rhesus monkeys. Endocrinology 109, 352-355. 